\title{
ATAQUES CON ÁCIDO: DESDIBUJADO EL CAMINO ENTRE LA IMPUTACIÓN FÁCTICA Y LA IMPUTACIÓN JURÍDICA EN EL DERECHO PENAL
}

\author{
Laura Andrea Acosta Zárate* \\ Ricardo Hernán Medina Rico*** \\ Los delitos deben ser calificados \\ según el daño infligido en la sociedad. \\ Cesare Beccaria
}

* Abogada de la Universidad del Rosario con profundización en Derecho Penal de la misma Universidad. Estudiante de la especialización en Ciencias Penales y Criminológicas de la Universidad Externado de Colombia. Ganadora del Concurso Nacional Universitario en Técnicas de Juicio Oral organizado por el Departamento de Justicia de la Embajada de los Estados Unidos de Norteamérica en Colombia y la agencia USAID (versión 2013-2014). Abogada litigante y consultora (Bogotá, Colombia). E-mail: lauraacostazarate@gmail.com

Abogado de la Universidad del Rosario, especialista en Derecho Penal de la Universidad del Rosario, especialista en Derecho Penal de la Universidad de Salamanca (España). Estudiante de la especialización en Derecho Administrativo de la Universidad del Rosario. Joven Investigador en Derecho Penal de la Universidad del Rosario. Tutor del equipo de la Universidad del Rosario, ganador del Concurso Nacional Universitario en Técnicas de Juicio Oral organizado por el Departamento de Justicia de la Embajada de los Estados Unidos de Norteamérica en Colombia y la agencia USAID (versión 2013-2014). Abogado litigante y profesor universitario (Bogotá,Colombia).E-mail: ricardo.medina@urosario.edu. co Fecha de recepción: 18 de noviembre de 2014. Fecha de modificación: 16 de diciembre de 2014. Fecha de aceptación: 16 de diciembre de 2014. Para citar el artículo: LAURA ANDREA AcOSTA ZÁRATE, RicARdo HERnÁN MEdina Rico. “Ataques con ácido: el desdibujado camino entre la imputación fáctica y la imputación jurídica en el derecho penal”, Revista Derecho Penal y Criminología, vol. 35 , n. ${ }^{\circ}$ 99, julio-diciembre de 2014, Bogotá, Universidad Externado de Colombia, 2014, pp. 61-87. DOI: http://dx.doi.org/10.18601/ 01210483.v35n99.03 
Resumen: El presente documento tiene como propósito hacer una evaluación pormenorizada de la actual situación que ha venido presentándose en el país frente a los ataques con ácido. Se hace un recorrido por las circunstancias sociales que hoy protagonizan este flagelo, el papel de las víctimas, del Estado y en especial del Congreso y su actividad como legislador. Adicionalmente, se hace alusión a las tres figuras jurídicas que han marcado las diferentes controversias normativas y doctrinales, estableciendo cuál de ellas se adecua de manera correcta a la situación.

Palabras clave: derecho penal, sanción penal, medios de comunicación, víctimas, problema social, aplicación de la ley.

\title{
ATTACKS WITH ACID: THE BLURRED PATH BETWEEN FACTUAL IMPUTATION AND LEGAL IMPUTATION IN CRIMINAL LAW
}

\begin{abstract}
The following document has the purpose of having a detailed evaluation of the present situation on Acid attacks that have been happening frequently in the country. This article will analyze the social circumstances, that prioritize this issue, the role of the victims, the State and specially the Congress and its activity as a legislator. Moreover, the three legal forms that have influenced the multiple legal and academic altercations will be discussed, establishing which of them work in pro of the situation.
\end{abstract}

Keywords: Criminal law, penal sanctions, mass media, victims, social problems, law enforcement.

\section{INTRODUCCIÓN}

En múltiples ocasiones la teoría pura del derecho penal parece apropiarse de los diferentes escenarios en donde se surten disputas jurídicas frente a la suerte de los agentes que incurren en conductas penalmente reprochables. No obstante, el mismo dinamismo de la sociedad, caracterizado por la influencia mediática, ha llevado a que sea este último el que -como una sustancia química altamente peligrosa- permee una dogmática jurídica estable y determinada; de tal modo que pueda ser adaptada -o corroída- a los diversos intereses políticos, sociales o personales.

Términos como ácido ortofosfórico, ácido fluorhídrico, ácido nítrico, ácido sulfúrico, hacen alusión a compuestos químicos altamente peligrosos que podrían perfectamente hacer parte de un estudio científico, médico, químico o biológico; empero, han logrado impregnar -con la misma peligrosidad- la "fragmentariedad" del derecho penal y se han convertido en protagonistas de los ataques que actualmente se presentan a diario en el país.

Partimos de la idea de una nueva moda. Nos encontramos frente a un mecanismo que se ha difundido cada vez más entre quienes lo utilizan; frente a una herramienta 
que ha servido para vender periódicos, elevar el raiting de noticieros y programas de crónicas, e incluso como sustento de proyectos de ley vagos y sin fundamento que, no obstante, han superado cada uno de los debates en el Congreso; un punto de partida que se destaca por no encontrar de dónde iniciar, pues como se verá en este texto, no existe claridad jurídica respecto de la correcta imputación que debe hacerse, de lo cual se desprende algo tan determinante como lo es la responsabilidad penal del autor.

En consecuencia de lo anterior, el presente estudio pretende delimitar dogmáticamente qué tipo de delito debe imputarse cuando existe un agresor que utiliza como instrumento de su lesión un ácido o una sustancia corrosiva; pretendiendo esgrimir las razones suficientes y lógicas que permitan una adecuada política criminal para acabar con esta situación reprochable y lograr la efectiva criminalización del punible en mención.

Para alcanzar este cometido se adelanta (I) un estudio de la situación existente en Colombia y de la problemática del fenómeno en los últimos años, para, a continuación, estudiar (II) el estado de la legislación colombiana en la materia, en particular las normas presentes en nuestro Código Penal, revisando posteriormente (IV) qué consecuencias trae considerar los ataques con ácido ora como tentativa de homicidio, ora como delito de tortura, ora como lesiones personales dolosas y agravadas; por último se presentan las conclusiones.

\section{SITUACIÓN ACTUAL EN COLOMBIA}

Un alarmante incremento de casos de ataques con ácido logró encender el interés de quienes hoy se encuentran involucrados de una u otra forma en el tema. Pese a la abundante divulgación de cifras a través de los medios de comunicación, hoy en día es todo un reto conocer un informe confiable y ponderado de los números ciertos que evidencian la realidad del fenómeno en el país.

Dado el impacto social del tema, no son pocos los medios de comunicación que han dado a conocer las cifras que aparentemente se encuentran en un reporte entregado por el Instituto Nacional de Medicina Legal; informe que revela un panorama a todas luces desalentador.

El 29 de marzo de 2014, la página oficial de la emisora Caracol Radio indicó que la cifra actual de víctimas por ataques con sustancias corrosivas asciende a 926. Según la noticia:

565 de las víctimas reportadas en un informe de Medicina Legal atacadas con ácido corresponden a mujeres y 297 están entre los 20 y 30 años de edad.

El informe que conoció Caracol Radio revela que 361 hombres fueron víctimas de esta clase de ataques y fue el año 2012 el que mayor número de denuncias registró con 162 casos. 
Entre 2004 y 2007 los ataques no sobrepasaban los 50 casos, a partir de 2008 se triplicaron las denuncias hasta llegar a un promedio de 160 ataques con ácido por año. Del total de los conocidos por la Fiscalía se estableció que 129 fueron perpetrados por miembros de la Fuerza Pública, entiéndase Policía, Ejército y hasta Inpec.

257 ataques fueron provocados por desconocidos a víctimas sin relación alguna con el agresor, en adelante el informe revela en cifras que 79 de estos ataques fueron de vecinos de las víctimas, 71 entre esposos y exesposos, 23 por delincuencia común, 49 entre compañeros de colegio y trabajo, 16 por arrendadores y clientes, 3 de empleados a jefes y 18 por supuestos amigos.

En el informe se entrega un reporte que sorprende por el parentesco de los agresores, 17 de estos ataques fueron de padres a sus hijos, 12 entre hermanos, 5 por niñeras, 2 de hijos a sus madres y 5 de cuñados.

168 víctimas de ataques con ácido son niños y un revelador dato indica que 28 eran menores de 4 y 3 años [sic] eran adultos mayores de 80 años. En 413 de estos casos el ácido fue arrojado en la cara, 91 en las manos mientras la víctimas intentaban protegerse, 35 en la cabeza y curiosamente 16 fueron en lo que se conoce como el área pélvica ${ }^{1}$.

De manera más reciente, el diario El Tiempo publicó que en el presente año se han registrado 16 ataques con ácido cuyo sujeto pasivo ha sido la mujer en la ciudad de Bogotá. Se hizo un comparativo con los últimos años que se presenta de la siguiente forma:

De acuerdo con el Instituto Nacional de Medicina Legal y Ciencias Forenses (INMLCF) durante 2012 se registraron 162 casos (94 mujeres, 58.02\%) y en el 2013, 69 casos (40 mujeres, 57.97\%) en todo el territorio nacional.

En el 2014 la Secretaría de Salud incorporó en el Sistema de Vigilancia Epidemiológica de Lesiones de Causa Externa (SIVELCE), la variable que permite identificar la agresión con agente químico o corrosivo.

Así fue que se supo que el año pasado se presentaron siete casos de personas quemadas con agente químico, de los cuales cinco fueron mujeres.

Entre enero y julio de 2014 se registraron solo en Bogotá un total de 15 casos de los cuales nueve fueron mujeres. "Lo anterior evidencia que a julio de 2014

1 "Desde 2004 en Colombia se denunciaron 926 ataques con ácido", Caracol Radio, 29 de marzo de 2014, obtenido el 3 de mayo de 2014, disponible en: [http://www.caracol.com.co/noticias/actualidad/8203desde2004-en-colombia-se-denunciaron-926-ataques-con-acido/20140329/nota/2152561 aspx] 
las agresiones en contra de las mujeres han incrementado en 80 por ciento", según la Secretaría de Salud².

Al respecto, la situación actual en Colombia no solo se enmarca en una serie de cifras publicadas por medios de comunicación. Hoy la coyuntura tiene tal envergadura que incluso ha llevado al gobierno nacional a ofrecer altísimas sumas de dinero con el fin de averiguar el paradero de los responsables; ha impulsado a llevar a cabo estudios de derecho comparado, en donde se han analizado las condiciones y circunstancias de realidades lejanas a la colombiana -aunque pareciera que solo en distancia-como lo es la de Pakistán ${ }^{3}$; y tristemente ha conseguido motivar a personas inescrupulosas que dicen ser víctimas de estos flagelos sin serlo con el propósito de gozar de las pocas prerrogativas que el Estado ha otorgado 4 .

Según cifras oficiales ${ }^{5}$ del Instituto Nacional de Medicina Legal y Ciencias Forenses, las víctimas del delito en cuestión corresponden al siguiente cuadro. Estos números hacen referencia a casos atendidos por el Instituto, pero este no dispone de las cifras de los ataques no reportados. Se enlistan no solo ataques con ácido sino también agresiones con cáusticos, bases y otros elementos que causen lesiones análogas.

\begin{tabular}{|c|c|c|c|}
\hline Año & Hombre & Mujer & Total \\
\hline 2004 & 20 & 25 & 45 \\
\hline 2005 & 7 & 9 & 16 \\
\hline 2006 & 24 & 27 & 51 \\
\hline 2007 & 25 & 28 & 53 \\
\hline 2008 & 76 & 66 & 142 \\
\hline 2009 & 56 & 70 & 126 \\
\hline
\end{tabular}

2 "Van 15 mujeres atacadas con ácido este año en Bogotá", El Tiempo, 5 de septiembre de 2014, obtenido el 8 de septiembre de 2014, disponible en: [http://www.eltiempo.com/bogota/van-15-mujeres-atacadascon-acido-este-ano/14486957].

3 “Ataques con ácido no son castigados en Pakistán”, El Tiempo, 5 de mayo de 2014, obtenido el 3 de mayo de 2014, disponible en: http://www.eltiempo.com/mundo/medio-oriente/ataques-con-acidono-son-castigados-en-pakistan/13937535].

4 "Publican audios de falsa denuncia de ataque con ácido", El Tiempo, 30 de abril de 2014, obtenido el 3 de mayo de 2014, disponible en: [http://www.eltiempo.com/bogota/publican-audios-de-falsavictima-de-ataque-con-acido/13837555].

5 Instituto Nacional de Medicina Legal y Ciencias Forenses. Requerimiento No. 560 - GCRNV - 2014. Cuadro n. ${ }^{\circ} 1$, Lesiones por quemadura con agente químico, según año del hecho y sexo de la víctima. Respuesta dada el 8 de septiembre de 2014 al derecho de petición elevado por Ricardo Medina el 3 de septiembre de 2014. 


\begin{tabular}{|c|c|c|c|}
\hline Año & Hombre & Mujer & Total \\
\hline 2010 & 77 & 63 & 140 \\
\hline 2011 & 73 & 49 & 122 \\
\hline 2012 & 68 & 94 & 162 \\
\hline 2013 & 29 & 40 & 69 \\
\hline 2014 & 3 & 6 & 9 \\
\hline Total & $\mathbf{4 5 7}$ & $\mathbf{4 7 5}$ & $\mathbf{9 3 2}$ \\
\hline
\end{tabular}

Fuente: Instituto Nacional de Medicina Legal y Ciencias Forenses - INMLCF / Grupo Centro de Referencia Nacional sobre Violencia - GCRNV. Bases: Sistema de Información de Clínica y Odontología Forense. SICLICO y Sistema de Información para el Análisis de la Violencia y la Accidentalidad en Colombia-SIAVAC ${ }^{6}$.

Ahora bien, el reproche por las conductas criminales enunciadas no ha sido únicamente objeto de indignación por parte de los medios de comunicación; es tal el terror que han generado en la colectividad, que los intentos por plantear soluciones viables han alcanzado todos los escenarios jurídicos en el país. Tal y como se muestra en el siguiente acápite, un sinfín de propuestas estancadas navegan hoy por las salas del Congreso colombiano, al parecer, sin rumbo fijo.

En conclusión, podemos ver las cifras alarmantes de víctimas de este flagelo. Tanto mujeres como hombres son sujetos pasivos de este tipo de lesiones. Los ataques con sustancias corrosivas dejaron de ser una excepción o una casualidad para requerir de un estudio jurídico-penal, criminológico y de política criminal serio que pretenda evitar al máximo las consecuencias nefastas de estos hechos.

\section{LEGISLACIÓN COLOMBIANA}

Como una colcha de retazos que poco a poco añade un nuevo ingrediente, se ha ido construyendo la legislación penal colombiana. Hoy parece que un nuevo elemento tiene la intención de introducirse a este compilado normativo. Dados los últimos acontecimientos, el legislador colombiano -y en general las autoridades estatalesse debate entre crear una figura autónoma o una regulación independiente que se encargue de normativizar y especialmente sancionar los casos de ataque con ácido, y la idea de fortalecer las normas ya existentes.

En un intento por enfrentar la situación y de algún modo buscar una solución al problema, surgió a la vida jurídica la Ley 1639 de 2013, mediante la cual el gobierno nacional desarrolló tres postulados que pretenden reglar el uso y comercialización

6 Información preliminar sujeta a cambios por actualización. Consultada el 5 de septiembre de 2014. 
de las sustancias empleadas para tales ataques, así como penalizar la indebida utilización de las mismas.

El primer y más importante elemento de esta ley está enfocado hacia el aumento de la pena prevista originalmente por la Ley 599 de 2000 frente al delito de lesiones personales, cuando de estas se derive una deformidad; es así como la ley introduce un agravante que deriva en un incremento en la sanción, de la siguiente forma:

Artículo 2. ${ }^{\circ}$ Modifíquese el artículo 113 de la Ley 599 de 2000 de la siguiente forma:

Artículo 113. Deformidad. Si el daño consistiere en deformidad física transitoria, la pena será de prisión de dieciséis (16) a ciento ocho (108) meses y multa de veinte (20) a treinta y siete punto cinco (37.5) salarios mínimos legales mensuales vigentes.

Si fuere permanente, la pena será de prisión de treinta y dos (32) a ciento veintiséis (126) meses y multa de treinta y cuatro punto sesenta y seis (34.66) a cincuenta y cuatro (54) salarios mínimos legales mensuales vigentes.

Si el daño consistiere en deformidad física causada usando cualquier tipo de ácidos; álcalis; sustancias similares o corrosivas que generen daño o destrucción al entrar en contacto con el tejido humano, incurrirá en pena de prisión de setenta y dos (72) a ciento veintiséis (126) meses y multa de treinta y cuatro punto sesenta y seis (34.66) a cincuenta y cuatro (54) salarios mínimos legales mensuales vigentes.

Si la deformidad afectare el rostro, la pena se aumentará desde una tercera parte hasta la mitad.

Al respecto, se hace imperioso advertir que si bien el derecho penal busca sancionar las conductas criminales que desestabilizan la sociedad, el penalizar la conducta no por la lesión en sí misma al bien jurídico, sino por el medio utilizado para llevarla a cabo, representa un exceso en lo que la doctrina ha establecido como fragmentariedad del derecho penal ${ }^{7}$; convierte entonces todo el proceso de tipificación de las conductas lesivas en un sistema desmedido de penalización.

Escribió el profesor VELÁSQUEZ con relación al tema en mención:

7 "La fragmentariedad del Derecho Penal indicaría entonces ante todo que sólo son punibles algunos fragmentos -más bien pocos, pero seleccionados no con criterios sistemáticos- del grupo de las conductas merecedoras de pena": AA.Vv. La insostenible situación del derecho penal. Comares, Granada, 2000,p. 390. 
Esta figura no tiene antecedentes en el derecho positivo ni tampoco se suele encontrar en los códigos penales de las naciones que se alinean en esta órbita cultural; no obstante, valga anotarlo, esta especie de lesiones personales ya estaba comprendida en las descripciones típicas existentes. Lo novedoso, por supuesto, es que el legislador -al hacer un llamado de atención al conglomerado social para que no se generalice tan reprobable conducta, muy propia de países árabes- diseñe un dispositivo específico para contemplarla y le imponga penas severas; previsiones legales encaminadas a prevenir estos atentados aparecen en la legislación penal de Bangladesh y se anuncian en las legislaciones de Camboya y Pakistán ${ }^{8}$.

La frustración colectiva en el país por la ocurrencia de estos hechos ha llevado a que este tipo de ataques lleguen a los encabezados de los periódicos, los titulares de los noticieros, las tantas promesas formuladas por políticos que buscan un puesto dentro del Congreso y, como ha quedado expuesto, en el centenar de leyes promulgadas, las cuales en nada logran ser una efectiva solución al problema, pero sí una latente deformidad para el derecho.

El segundo postulado dispuesto en la Ley 1639 se enmarca en la creación de un Registro de Control de Ventas de sustancias químicas, en cabeza del Instituto Nacional de Vigilancia de Medicamentos y Alimentos (INVIMA); una entidad con tal organización que será la encargada de efectuar un seguimiento detenido de los actores involucrados en la relación de comercialización del producto y de la procedencia de los mismos.

Tal es la ambición del legislador, que dentro de su ideal de regulación de la sustancia incluyó dos sanciones adicionales a la ya enunciada previamente. La primera de ellas está dirigida a los establecimientos de comercio que adelanten la comercialización de las sustancias previstas como lesivas sin observar las previsiones que el Registro de Ventas prevé, y la segunda -la cual reviste especial curiosidad- estima una prohibición específica para quienes bajo el estado de alicoramiento, de sustancias psicoactivas o siendo menores de edad, porten sustancias químicas restringidas; y aunque al lector no le es dada la interpretación de la norma, sí surge la duda frente al porte "ilegal" de sustancias químicas dañosas para el tejido humano respecto de sujetos que no se encuentren inmersos en tales condiciones. ¿Puede una persona capaz portar sustancias químicas corrosivas?

Finalmente, le ley en comento incluye un acápite completo dedicado a la atención integral a las víctimas de ataques con ácido; tan utópico como el anterior, con este se pretende implementar una Ruta Integral de atención de los casos; sin especificación alguna, el legislador puso de presente que esta medida estaría direccionada a

8 Velásquez, FeRnando. Delitos contra la vida y la integridad personal. Ediciones Jurídicas Andrés Morales, 2013,pp. 252 y 253. 
“suministrar información y orientar a las víctimas acerca de los derechos, medidas y recursos con los que cuenta, los medios judiciales, administrativos y de atención en salud"9, así como el seguimiento de las víctimas durante el proceso de recuperación de sus trabajos y vida en sociedad.

Una fantasía que el legislador concluyó al desplazar la responsabilidad del suministro de "los servicios, tratamientos médicos y psicológicos, procedimientos e intervenciones necesarias para restituir la fisionomía y funcionalidad de las zonas afectadas" en cabeza de un sistema de salud del Estado que no puede ser más problemático e insuficiente.

Sin dejar de ser más traumático para las víctimas y para el sistema, el legislador determinó un período de 6 meses para la reglamentación de las medidas adoptadas en esta ley, misma que fue promulgada el 2 de julio de 2013, instante en el cual entró en vigencia y desde el que se contaría dicho término; no obstante, hasta el momento no existe reglamentación alguna de esta ley, pero paradójicamente sí se han puesto sobre la mesa otros proyectos de ley que al parecer buscan ser una solución para las víctimas y no una respuesta a la coyuntura actual.

\section{III. ¿TENTATIVA DE HOMICIDIO, LESIONES PERSONALES AGRAVADAS O TORTURA?}

La problemática actual ha llevado hasta el escenario judicial la disyuntiva frente a la tipificación de la conducta de ataque con ácido. Los casos de reciente ocurrencia han planteado -debido a sus características- un álgido debate frente a la tipificación del injusto por el cual debe procesarse a los autores de este flagelo; figuras como la tentativa de homicidio, las lesiones personales agravadas y la tortura han sido protagonistas de un maremágnum jurídico, doctrinal y mediático que por demás ha logrado desarrollar las más complejas estrategias de defensa y la desmedida utilización de figuras jurídicas tendientes a buscar un eximente de responsabilidad.

Los entes jurídicos que han cobrado una trascendencia especial frente a los ataques con ácido se muestran a continuación.

\section{i. Tentativa de homicidio}

Una situación de considerable connotación, las características mismas de la conducta penalmente reprochable e incluso el mismo populismo punitivo han llevado a pensar que este tipo de vejámenes se enmarcan de mejor manera bajo el postulado planteado por uno de los dispositivos amplificadores del tipo: la tentativa. Por tal razón,

9 Artículo 4. ${ }^{\circ}$ Ley 1639 de 2013.

10 Artículo 5. ${ }^{\circ}$ Ley 1639 de 2013. 
se hace imperiosa la necesidad de establecer el concepto propio de la tentativa, sus elementos y clasificaciones. Veamos.

Uno de los yerros de mayor ocurrencia es la remisión al estatuto penal colombiano esperando encontrar un delito que responda al nombre de "tentativa de homicidio" o "tentativa de hurto"; es de saber que la tentativa en sí misma no encuentra una tipificación propia dentro del Código Penal, por el contrario, hace alusión a una extensión de la conducta que busca ser tipificada. En palabras de Fernando Velásquez: "no significa que la naturaleza jurídica de la tentativa equivalga a la de un tipo delictivo distinto del que prevé un delito o conducta punible consumada, sino que se trata sencillamente, de una figura que implica una extensión de la tipicidad básica, como una forma especial de configuración del tipo o de su dispositivo amplificador"11. Esta amplificación de la tipicidad permite que no solo los delitos consumados logren ser penalizados, sino que estos encuentren sanción incluso en etapas previas, durante lo que la escuela clásica ha reconocido como iter criminis ${ }^{12}$; este recorrido criminal cuenta con una serie de fases de las cuales se deriva responsabilidad para el autor, y otras que simplemente hacen parte del proceso criminal, mismas que al no generar un efecto en el mundo jurídico, no son penalizadas por el ordenamiento.

La primera etapa del hecho punible se conoce como ideación, durante la cual la idea criminal únicamente existe en la mente del autor y aun no cobra una implicación penal: "esta etapa no es punible en ningún caso, pues rige el principio de que el pensamiento no delinque"13; le sigue la fase de preparación, en la cual el autor del punible consigue, revisa e identifica los medios que utilizará durante la ejecución de la conducta; al igual que la etapa de ideación, la preparación no tiene una incidencia jurídica directa, salvo que la acción desplegada encuentre asidero en el ordenamiento jurídico al estar tipificada como un tipo penal; estas dos etapas hacen parte de lo que la doctrina y la jurisprudencia han reconocido como parte de la fase interna del iter criminis, mientras que la fase externa se encuentra conformada por la fase de ejecución, entendida como aquella en la cual el actor despliega y pone en uso los medios que previamente anticipó para el desarrollo de la conducta; para finalmente llegar a la etapa de consumación, escenario en el cual se materializa el resultado de la conducta ideada por el autor. No obstante, es preciso señalar que "la tentativa, necesariamente, debe ubicarse en la tercera etapa del recorrido criminal, es decir, en la fase de ejecución, por cuanto, como ya dijimos, los actos preparatorios

11 Velásquez, Fernando. Manual de Derecho Penal. Parte General. Librería Jurídica Comlibros, Medellín, 2007

12 Córdoba Angulo, Miguel. Lecciones de Derecho Penal. Parte General. Universidad Externado de Colombia, 2011, p. 309.

13 Ibíd. 
no son punibles, y el último paso daría lugar a una conducta punible consumada mas no tentada" 14 .

La legislación colombiana ha adoptado el concepto de tentativa en el artículo 27 de la Ley 599 de 2000, de la siguiente forma:

Artículo 27. Tentativa. El que iniciare la ejecución de una conducta punible mediante actos idóneos e inequívocamente dirigidos a su consumación, y ésta no se produjere por circunstancias ajenas a su voluntad, incurrirá en pena no menor de la mitad del mínimo ni mayor de las tres cuartas partes del máximo de la señalada para la conducta punible consumada.

Cuando la conducta punible no se consuma por circunstancias ajenas a la voluntad del autor o partícipe, incurrirá en pena no menor de la tercera parte del mínimo ni mayor de las dos terceras partes del máximo de la señalada para su consumación, si voluntariamente ha realizado todos los esfuerzos necesarios para impedirla.

Tal como se extrae del texto citado, esta modalidad de ilícito cuenta con elementos específicos para su configuración; el primer elemento indispensable para que exista la tentativa hace alusión al propósito de cometer la conducta o el hecho punible. Al respecto, la jurisprudencia colombiana ha establecido:

En este caso, el sujeto tiene la intención o idea criminosa de dar muerte a la otra, mediante la exteriorización del pensamiento o a través de la deducción que se hace sobre el comportamiento del actor, en cuanto debe establecerse que tenía intención homicida, lo cual se hace bajo el análisis de la forma como se actuó, los medios que utilizó o la magnitud del daño que alcanzó a producir, si eventualmente se produce la lesión al bien jurídico protegido ${ }^{15}$.

Este propósito o idea criminal se resume en uno de los lineamientos esenciales para la existencia de la tentativa; así el dolo dentro de la acción se convierte en un ingrediente determinante a la hora de establecer una diferencia entre este dispositivo amplificador y otro tipo de figuras jurídicas como por ejemplo el injusto de lesiones personales agravadas o la tortura.

Cobra entonces especial trascendencia el concepto de animus necandi, o ánimo doloso de matar, mediante el cual se evalúa la intención del agente de cometer el delito. Dentro del examen en sede de tipicidad, "ha de acudirse al injusto subjetivo, esto es,

14 Ibíd., p. 310.

15 Juzgado Quinto Penal del Circuito de Santa Marta, sentencia del 17 de julio de 2000, causa n. . 20000057 . 
el ánimo o dolo que impulsó al agente a tal comportamiento, pues dada la dificultad que entraña el indagar sobre un dato psicológico, se hace preciso acudir a los signos reveladores de la verdadera voluntad del sujeto activo, datos de carácter objetivo que exterioricen la desconocida intención del infractor" 16.

No basta entonces, para que se configure el delito de homicidio en grado de tentativa, la vulneración al bien jurídico, distinto los tipos penales de lesiones personales agravadas y del de tortura, dentro del homicidio debe poder dilucidarse un ánimo diáfano en la conciencia del agente de la intención de acabar con la vida de su víctima.

La idoneidad e inequívoca utilización de medios idóneos constituye el tercero de los elementos necesarios para la configuración del injusto en grado de tentativa: "este aspecto se analiza bajo dos perspectivas: la primera en el plano objetivo, esto es, el hecho concreto que se ejecuta es la manifestación de la conducta al mundo real por medio de actos que tengan la virtualidad efectiva de producir el resultado antijurídico" ${ }^{17}$.

Frente al caso que nos ocupa, de la utilización de sustancias corrosivas de alta peligrosidad para el ser humano, su bienestar y salud, las lesiones generadas en regiones faciales, miembros u órganos vitales, se decanta la inminente intención del agresor no solo de causarle un daño físico a su agredido, sino de acabar con su vida mediante la acción. La tentativa también lleva inmerso un elemento subjetivo, el cual "no difiere en nada del tipo subjetivo del delito consumado; es decir, el dolo y los elementos subjetivos distintos del dolo que se requieren en el delito consumado son también exigidos en el delito tentado. Esta identidad del tipo subjetivo nos confirma de que el delito tentado es un delito incompleto: tipicidad subjetiva completa, con defecto en la tipicidad objetiva"18.

El último de los elementos de la tentativa está dado por las características mismas de la actuación; al ser una acción truncada, se materializa el elemento siempre que el resultado no se agote por circunstancias ajenas a la voluntad del agente; "aquí podemos hablar de la ruptura del nexo causal entre el resultado deseado y el materialmente producido, bajo una óptica eminentemente instrumental, o sea, mediante una fórmula objetiva que obstaculiza el desenlace finalmente querido, por cuanto se superponen, ya sea a la conducta, o al mismo hecho, determinadas eventualidades que truncan el proceso del iter criminis"19.

16 Ruiz, Urbano. Diccionario Índice de Jurisprudencia Penal, t. III. Ministerio de Justicia e Interior, España, 1989-1992.

17 Juzgado Quinto Penal del Circuito de Santa Marta, sentencia del 17 de julio de 2000, causa n.$^{\circ} 2000$ 0057.

18 Zaffaroni, Eugenio Raúl. Tratado de Derecho Penal. Parte General. Ediar, 1980, p. 434.

19 Juzgado Quinto Penal del Circuito de Santa Marta, sentencia del 17 de julio de 2000, causa n. 2000 0057. 
Pese a que el artículo 27 de nuestro estatuto penal solo prevé dos de las clasificaciones de la tentativa, la doctrina ha establecido cuatro modalidades distintas que enmarcan las circunstancias por las cuales la actuación puede verse obstaculizada degenerando la conducta en un delito incompleto. La primera de ellas es la tentativa inacabada, la cual se presenta cuando "se da comienzo a la ejecución del hecho pero el resultado no se logra por una circunstancia ajena a la voluntad del sujeto agente"20. Por oposición, la doctrina ha señalado una segunda clasificación que corresponde a la tentativa acabada, la cual advierte desde sus características objetivas que "pone el punto de vista en la secuencia de actos verificada antes de la interrupción forzada del hecho, de modo que si se han practicado todos aquellos actos que deberían dar como resultado el delito, y éste no se produce en todas sus consecuencias por causas ajenas a la voluntad del culpable, estamos en presencia de la tentativa acabada" 21 . La tercera clasificación se conoce como tentativa imposible: “también llamada 'idónea', es la de que la no consumación del hecho no se debe ni a la presencia de factores endógenos o exógenos que paralicen involuntariamente la acción comenzada, ni la propia determinación del agente, sino a completa idoneidad de la conducta para alcanzar el fin propuesto o inexistencia o falta de cualificación típicamente exigida del objeto material o del sujeto pasivo" ${ }^{22}$. Finalmente, se tiene la tentativa desistida, figura que se presenta "cuando un individuo, con el propósito de cometer una conducta punible, da inicio a la ejecución pero voluntariamente se abstiene de consumar el hecho, pudiendo hacerlo" 23 .

Expuesto lo anterior se precisa que los ataques con ácido difícilmente podrían imputarse a título de tentativa de homicidio; lo anterior, teniendo en cuenta que no siempre concurrirán los elementos del tipo en el agresor, en especial el dolo de matar que exige la conducta. La imputación jurídica conllevaría problemas probatorios para el órgano instructor si se considera que, como se ha podido ver a través de los distintos medios de comunicación, los ataques con agentes corrosivos suelen tener como trasfondo venganzas pasionales, ánimos de lesión, intencionalidad de dañar la corporalidad de la víctima, pero no buscan privar de la vida al agredido, por el contrario, las secuelas del ataque son la forma de obligar a recordar la represalia en que consistiría la agresión.

Al momento de ejecutar el ataque, no siempre se premedita el acto para que atente contra la vida; es más, en la mayoría de los casos el sujeto activo decide arrojar sobre la humanidad del sujeto pasivo la sustancia sin importar en qué parte caiga (ropa, cara,

20 Córdoba Angulo, Miguel. Lecciones de Derecho Penal. Parte General. Universidad Externado de Colombia, 2011, p. 314.

21 Sentencia T.S. 1070/2011 (Sala 2) del 13 de octubre de 2011, Villa de Madrid, España.

22 Reyes Echandía, Alfonso. Tipicidad, 5. a ed. Temis, 1989, p. 160.

23 Córdoba Angulo, Miguel. Lecciones de Derecho Penal. Parte General. Universidad Externado de Colombia, 2011, p. 316. 
extremidades), por cuanto su finalidad es ocasionar un mal, sin importar cuál sea. No siempre se desea que la víctima ingiera el ácido (cuestión que ya ha ocurrido) o que las quemaduras sean de alto nivel en todo el cuerpo, lo que llevaría a la muerte del sujeto. Si no existe el animus necandi expuesto con anterioridad, difícilmente existiría congruencia entre la imputación jurídica y la realidad fáctica, lo cual generaría una absolución en el juicio penal bajo la óptica de la legalidad misma.

Así las cosas, queda claro cómo la tentativa -como dispositivo amplificador del tipo penal- cuenta con elementos completamente distintos a los que se enunciaran en los dos tipos penales de lesiones personales y tortura, y por tanto no debe convertirse en un mecanismo de represión o prevención general negativa ${ }^{24}$ por parte del Estado, generando equívocamente un estadio de inseguridad jurídica para los procesados. Sin lugar a dudas, la tentativa de homicidio es el primer camino desdibujado entre la imputación fáctica y la imputación jurídica de las agresiones con ácido en la realidad colombiana.

\section{ii. Tortura}

Como segundo tipo penal que ha logrado ocupar un espacio dentro de los debates judiciales y académicos alrededor de los casos de reciente ocurrencia se ha plasmado el delito de tortura. En un recorrido por las diversas medidas adoptadas frente a la coyuntura actual, vale la pena resaltar la intención promovida por el Presidente del Senado de la República de elevar este tipo de crímenes a la calificación de delitos de lesa humanidad; no obstante, pareciera una vez más que este tipo de propuestas responden al clamor de un populismo punitivo desesperado, y no a la certeza de un derecho penal concreto.

El delito de tortura, el cual actualmente hace parte del compilado del ius cogens, ha ocupado amplios espacios a nivel nacional e internacional, con lo que se ha pretendido fijar un concepto puntual frente a la materia, además de un extenso desarrollo de aplicación jurisprudencial y doctrinal. De esta manera, la Convención Interamericana para Prevenir y Sancionar la Tortura, en su artículo 2, estableció:

Para los efectos de la presente Convención se entenderá por tortura todo acto realizado intencionalmente por el cual se inflijan a una persona penas o sufrimientos físicos o mentales, con fines de investigación criminal, como medio intimidatorio, como castigo personal, como medida preventiva, como pena o con cualquier otro fin. Se entenderá’ también como tortura la aplicación sobre una persona de métodos tendientes a anular la personalidad de la

24 Ruiz, Carmen Eloísa. Lecciones de Derecho Penal. Parte General. Universidad Externado de Colombia, 2011, p. 32. 
víctima o a disminuir su capacidad física o mental, aunque no causen dolor físico o angustia psíquica.

La afanada propuesta del congresista merece un análisis pormenorizado, de tal manera que sea posible establecer que frente a los casos de ataques con ácido -aunque sea necesaria una penalización más contundente- no es procedente considerar la conducta como de aquellas que hacen parte de los delitos contra la humanidad. Veamos.

Son muchos los casos que han sido materia de investigación en la Corte Interamericana de Derechos Humanos, la Comisión Interamericana y los diferentes tribunales ad hoc, los cuales han hecho un amplio estudio del tema. Respecto del lugar que ocupa el delito de tortura dentro de los delitos de lesa humanidad, vale la pena hacer una remisión al caso Akayesu ${ }^{25}$ del Tribunal Penal Internacional para Ruanda, en donde se establecen como requisitos de la tortura, para que sea considerada crimen de lesa humanidad: (a) la tortura debe ser perpetrada como parte de un ataque generalizado o sistemático; (b) debe dirigirse contra la población civil; (c) el ataque debe ser discriminatorio por razones de nacionalidad o por razones políticas, étnicas, raciales o religiosas. Terra entonces el parlamentario en mención al intentar elevar los casos de ataques con ácido como constituyentes del delito de tortura, y ello si se considera que este tipo de vejámenes no son de carácter sistematizado y continuo; es más, en su gran mayoría son simplemente producto de un impulso por parte del sujeto activo de la conducta; tampoco revisten la condición de ser impulsados por razones de raza, nacionalidad o etnia, y no existe un común denominador entre las víctimas que lleve a establecer que dichas conductas lesivas se encuentran dirigidas a una población en particular.

No obstante, no son solo estos los elementos propios del delito de tortura. La Corte Interamericana de Derechos Humanos, en sentencia del 11 de mayo de $2007^{[26]}$, indicó: "La Corte entiende que los elementos constitutivos de la tortura son los siguientes: a) un acto intencional; b) que cause severos sufrimientos físicos o mentales, y c) que se cometa con determinado fin o propósito".

Cada uno de los elementos enunciados se encuentra materializado en las conductas cometidas con sustancias químicas; es evidente que los diferentes agentes que han utilizado este tipo de medios en sus actuaciones han tenido la intención, de manera clara se ha visto como las víctimas han sido sometidas a padecimientos atroces tanto físicos como morales, y ha sido posible además verificar que cada uno de los atentados ha tenido un propósito determinado. A simple vista podría señalarse que la propuesta en cuestión encuentra resorte en los elementos enunciados por las instancias inter-

25 International Criminal Tribunal for Rwanda. The Prosecutor v. Jean-Paul Akayesu, case No. ICTR96-4-T, September 2nd 1998.

26 Corte Interamericana de Derechos Humanos, caso Bueno Alves vs. Argentina. 
nacionales, sin embargo la falta de continuidad y la ausencia de sistematización del flagelo frente a una misma víctima constituye el elemento determinante que logra desnaturalizar el ideal de inclusión de los ataques con sustancias químicas lesivas para el tejido humano, como delito de tortura.

Ahora bien, si nos circunscribimos a lo consagrado en el ordenamiento jurídico colombiano, es menester revisar el artículo 178 del estatuto penal y así estudiar los elementos del tipo, tanto su parte objetiva como la subjetiva. El artículo en mención expresa:

Artículo 178. Tortura. El que inflija a una persona dolores o sufrimientos, físicos o psíquicos, con el fin de obtener de ella o de un tercero información o confesión, de castigarla por un acto por ella cometido o que se sospeche que ha cometido o de intimidarla o coaccionarla por cualquier razón que comporte algún tipo de discriminación incurrirá en prisión de 128 meses a 270 meses, multa de 1066.66 a 3.000 salarios mínimos legales vigentes e inhabilitación para el ejercicio de derechos y funciones públicas por el mismo término de la pena privativa de la libertad.

En la misma pena incurrirá el que cometa la conducta con fines distintos a los descritos en el inciso anterior.

No se entenderá por tortura el dolor o los sufrimientos que se deriven únicamente de sanciones lícitas o que sean consecuencia normal o inherente a ellas.

A la luz de lo expuesto, podría afirmarse que la conducta enunciada en el tipo penal en comento sí se satisface con los ataques con ácido. No cabe la menor duda de que una agresión de ese tipo genera o inflige a otro ser humano dolores o sufrimientos, tanto físicos como psíquicos, razón por la cual hasta este momento encontraría respaldo la imputación jurídica de la acción criminal.

Resulta necesario entonces revisar el elemento subjetivo requerido en el tipo penal de tortura, de tal forma que pueda ser evaluado frente a la conducta penalmente reprochable de los ataques con ácido. Así pues, al tomar como punto de partida la información suministrada a través de los medios de comunicación, jamás se ha visto como fin del vejamen obtener información o confesión ni del agredido ni de una tercera persona; por tal razón, la primera finalidad es descartada de tajo. En segundo término se pretende constatar un castigo por un acto cometido o que se sospeche que se ha cometido; no obstante, este elemento representa un reto aún más difícil para el ente acusador en términos de prueba, pues es sumamente complejo demostrar que el acto ha sido ejecutado a raíz de una motivación vengativa, y en este sentido un imputación de esta índole llevaría a una clara ambigüedad probatoria.

En el mismo tenor anterior se encuentra el elemento "intimidarla o coaccionarla por cualquier razón que comporte algún tipo de discriminación”. El primer elemento es 
posible identificarlo, por ejemplo, en los casos en donde este tipo de sustancias químicas son utilizadas como herramienta para llevar a cabo delitos de hurto; el problema es el segundo apartado del elemento subjetivo, ya que requiere "comportar algún tipo de discriminación”, lo cual no es sustentable en los ataques con ácido, pues bajo los presupuestos fácticos que han podido conocerse, no existe discriminación alguna en razón de raza, religión o ideología que lleve a la configuración de estas conductas; y habría que reconocer que si bien existe un porcentaje mayor de víctimas mujeres que hombres, este no puede ser un patrón fijo que lleve a una directa imputación en razón de esta condición. Nuevamente se estaría ante una vaguedad que no tiene soporte fáctico ni demostrativo al momento de probar.

Queda entonces el segundo inciso del artículo, presupuesto en donde encuentran sustento aquellos que alegan la tortura como forma de lucha contra los ilícitos sujeto de estudio. Aquí quedaría satisfecho el ataque, ya que se requiere como finalidad un "fin distinto de los descritos en el inciso anterior”; allí se ampararía cualquier objetivo y cualquier intención que se haya tenido contra la víctima. ¿Podría hallarse sustento entonces para esta imputación jurídica?

Con el ánimo de dar respuesta a este interrogante, es necesario señalar que dicho respaldo jurídico resultaría impropio por cuanto, a pesar de satisfacer en principio la lectura del tipo penal, el bien jurídico protegido por la tortura no engloba lo acaecido en un ataque con ácido. El delito de tortura se encuentra en el Título III del Código Penal el cual se intitula "Delitos contra la libertad individual y otras garantías", y específicamente en el capítulo quinto que lleva por nombre "De los delitos contra la autonomía personal”. Así pues, el delito de tortura atenta contra el bien jurídico de la autonomía personal.

Este bien jurídico ha sido denominado por diferentes autores como "una aplicación de la libertad de la persona a fin de que esta dirija y controle su conducta, de modo que no solo implica capacidad de desplazarse materialmente de un lugar a otro, sino disposición de determinarse independientemente de todo lo referente a la génesis y contenido de las decisiones" 27 .

En los ataques con ácido lo lesionado va más allá del interés protegido con la autonomía personal. Si se considera el bien jurídico de manera más amplia, englobando conceptos de integridad personal y dignidad humana como lo señala la sentencia C-587 de 1992, podría encontrarse marco para la tortura, pero, haciendo una interpretación restrictiva y acorde a la ubicación sistemática del delito dentro del Código Penal, se estaría dejando por fuera toda una globalidad que quizás con otra imputación jurídica se satisface.

27 Pérez, Luis Carlos. Derecho Penal. Partes General y Especial, t. IV. Temis, 1985, p. 401. 
Por lo analizado con anterioridad, considerar los ataques con sustancia ácida como constitutivos del delito de tortura genera problemas probatorios, dificultad de determinación de la finalidad (a menos que sea tratada por el segundo inciso del artículo 178 del Código Penal) y, en especial, un indebido tratamiento del bien jurídico tutelado. Se pretendería utilizar el derecho penal como vehículo del populismo electoral y se desdibujarían los principios rectores y los límites formales y materiales del estudio jurídico penal. Estaríamos en presencia de un segundo desdibujado camino entre la imputación fáctica y la jurídica en este tipo de agresiones.

\section{iii. Lesiones personales}

Al igual que la tentativa, el tipo penal de lesiones personales requiere de un examen detallado, pues como se establecerá ampliamente más adelante, es este concretamente el delito por el cual deben ser procesados los individuos que utilizan sustancias químicas como el ácido, como mecanismo para perpetrar diferentes atentados contra sus víctimas.

El delito de lesiones personales no es de reciente tipificación ${ }^{28}$ en nuestra legislación, ni mucho menos es de consagración única en Colombia ${ }^{29}$. Deben considerarse las lesiones personales como "todo daño en el cuerpo o en la salud física o mental de una persona, causado por acción dolosa o culposa de otra, sin intención de matar" 30 . Esta conducta punible pretende la protección de la integridad personal como bien jurídico sujeto a tutela. Al respecto Alfonso Gómez Méndez escribió: "Se habla pues de delitos contra la 'integridad personal', por cuanto las conductas que a ellos se refieren lesionan o ponen en peligro esa unidad (física, anatómica, estética, síquica, etc.) que le permite al sujeto desenvolverse en el medio social, sin limitaciones de ninguna especie, en los órdenes físico y síquico"31.

En la actualidad, la Ley 599 de 2000 incorporó el delito de lesiones personales en su artículo 111, el cual señala: "Artículo 111. Lesiones. El que cause a otro daño en el cuerpo o en la salud, incurrirá en las sanciones establecidas en los artículos siguientes”.

28 Para un recuento histórico del delito en Colombia, cfr. GómEz MÉndEz, ALFonso. Delitos contra la vida y la integridad personal, 3. ${ }^{\text {a }}$ ed. Universidad Externado de Colombia, 1998, pp. 303 a 306.

29 Para un análisis de derecho comparado frente al delito de lesiones personales cfr. BARRERA DOMÍNGUEZ, Humberto. Delitos contra la vida y la integridad personal. Ediciones Librería del Profesional, 1995, pp. 119 a 122.

30 Mesa Velásquez, Luis EduARdo. Delitos contra la vida y la integridad personal y delitos contra la propiedad. Universidad de Antioquia, 1968, p. 57. De la misma forma es definido por FERNANDO VELÁSQUEZ VeLÁSQUEZ en su libro Delitos contra la vida y la integridad personal. Ediciones Jurídicas Andrés Morales, 2013, p. 239.

31 Gómez Méndez, Alfonso. Delitos contra la vida y la integridad personal. 3. a ed. Universidad Externado de Colombia, 1998, p. 301. 
No obstante, el concepto de lesiones personales no se agota únicamente en el mencionado artículo; el Código es claro en señalar las diferentes modalidades bajo las cuales se pueden presentar las lesiones personales, de las cuales cada una reviste una incidencia punitiva diferente dentro del ordenamiento.

La primera tipología referida en la ley es la de incapacidad para trabajar o enfermedad $^{32}$; pese a los debates científicos y dogmáticos frente a esta y el concepto de perturbación funcional, se ha entendido como incapacidad: "el tiempo necesario para que la parte orgánica que ha sido afectada por las lesiones, recupere su antigua vitalidad"33 o "la carencia de aptitud legal para efectuar válidamente determinados actos o para ejercer determinados oficios públicos" 34 . Acogemos la primera posición, pues la segunda es una incapacidad general y no tiene en cuenta la remisión al carácter laboral de la misma.

Adicionalmente, se debe considerar si la incapacidad es especial, remitida a la incapacidad para realizar la labor que realiza específicamente el individuo ${ }^{35}$, o general, es decir, "para cualquier clase de trabajo, físico o intelectual" 36 , postura que acogemos, pues además de que la norma no hace distinciones, si analizáramos una incapacidad especial llegaríamos a extremos como afirmar que la lesión causada a un desempleado es irrelevante ${ }^{37}$.

Del mismo modo, el código establece una segunda modalidad: la deformidad ${ }^{38}$. Puesto que es este modo el más significativo para el tema de este escrito, es necesario hacer unas precisiones importantes. En primer lugar, tanto la jurisprudencia colombiana

32 “Artículo 112. Incapacidad para trabajar o enfermedad. Si el daño consistiere en incapacidad para trabajar o en enfermedad que no pase de treinta (30) días, la pena será de prisión de uno (1) a dos (2) años. Si el daño consistiere en incapacidad para trabajar o enfermedad superior a treinta (30) días sin exceder de noventa (90), la pena será de uno (1) a tres (3) años de prisión y multa de cinco (5) a diez (10) salarios mínimos legales mensuales vigentes. Si pasare de noventa (90) días, la pena será de dos (2) a cinco (5) años de prisión y multa de diez (10) a veinte (20) salarios mínimos legales mensuales vigentes".

33 Arboleda Vallejo, Mario y Ruiz Salazar, José Armando. Manual de Derecho Penal. Leyer, 2007, p. 633.

34 Solórzano Niño, Roberto. Medicina legal, criminalística y toxicología para abogados. Canal Ramírez, 1996, p. 120.

35 Por ejemplo en una lesión de las manos la incapacidad sería mayor en un pianista que en un cantante.

36 Uribe Cualla, Guillermo. Medicina legal, toxicología y siquiatría forense. Temis, p. 263.

37 Castro Cuenca, Carlos Guillermo. Manual de Derecho Penal. Parte Especial. Colegio Mayor de Nuestra Señora del Rosario, 2010, p. 137.

38 "Artículo 113. Deformidad. Si el daño consistiere en deformidad física transitoria, la pena será de prisión de uno (1) a seis (6) años y multa de quince (15) a veinticinco (25) salarios mínimos legales mensuales vigentes. Si fuere permanente, la pena será de prisión de dos (2) a siete (7) años y multa de veintiséis (26) a treinta y seis (36) salarios mínimos legales mensuales vigentes.

"Si la deformidad afectare el rostro, la pena se aumentará hasta en una tercera parte". 
como los fallos internacionales la han reconocido como: "toda irregularidad física, visible y permanente, que suponga desfiguración o fealdad ostensible a simple vista" 39 . Es evidente la trascendencia que tiene para la víctima que la agresión sea dirigida al área del rostro, pues "la deformidad estriba en una imperfección estética que rompe la armonía facial y por tanto visible y permanente, alterando la morfología de la cara" ${ }^{40}$.

Es tan importante el análisis de la deformación de la cara que en legislaciones anteriore $^{41}$ una de las formas de tipificar las lesiones personales calificadas era aquella que se denominaba lesiones que producen deformidad física o desfiguración facial, la cual doctrinalmente era definida como "la alteración sensible de la estética del rostro o irregularidad en las formas faciales, v.gr., cicatrices notorias en la cara, pérdida total o parcial del pabellón de la oreja, deformaciones de los labios, etc. El rostro es la parte anterior de la cabeza, desde la frente hasta el extremo del mentón y con inclusión de las orejas" ${ }^{42}$. En el mismo sentir escribe otro tratadista:

... en medicina legal se entiende por deformidad física todo efecto que cambie la integridad, la proporción, el orden o la armonía que normalmente tienen o guardan entre sí las partes constitutivas del cuerpo humano, en su configuración exterior. Es decir, que todo aquello que altere la modalidad normal con la que proporcionalmente intervienen los elementos objetivos de la belleza en la constitución de lo que acostumbramos llamar las formas, constituye una deformidad física. Este cambio puede afectar la hermosura del semblante y las facciones, constituyendo entonces lo que algunos califican como la desfiguración; o bien la esbeltez, soltura y elegancia del cuerpo, en reposo o en movimiento, que es lo que constituye la deformidad propiamente dicha. [...] Desfiguración es el cambio, pero en el semblante, en el rostro. Desfiguración es, dice Lacassagne, citado por Uribe Cualla, la consecuencia aparente de una herida que está situada en el rostro o en sus inmediaciones y que modifica su color, su forma, o sus funciones de expresión ${ }^{43}$.

Ahora bien, hoy por hoy la situación resultante del delito de lesiones personales cuando hay deformidad en el rostro no ha perdido vigencia. Como se ha notado, los ataques indiscriminados con ácidos casi siempre van dirigidos a la cara de la víctima. En consecuencia, dado el impacto social que los ataques con ácido han tenido en el

39 Juzgado de Violencia sobre la Mujer n. ${ }^{\circ} 3$ de Madrid, Sentencia 252/2014, Sección n. ${ }^{\circ} 26$ de la Audiencia Provincial de Madrid, Procedimiento sumario ordinario 14/2013, Magistradas D. Teresa Arconada Viguera, D. Pilar Alhambra Pérez y D. Leopoldo Puente Segura.

40 Ibíd.

41 Código Penal de Colombia de 1936, art. 373.

42 Mesa Velásquez, Luis EduARdo. Delitos contra la vida y la integridad personal y delitos contra la propiedad. Universidad de Antioquia, 1968, p. 62.

43 Barrientos Restrepo, Samuel. Delitos contra la vida y la integridad personal. Bedout, 1965, p. 178 
país y el manejo que los funcionarios judiciales han dado a los casos, el legislador colombiano ha promovido una transformación en temas de punibilidad, así como la creación o delegación a un agente estatal de la responsabilidad del control y vigilancia de la comercialización de este tipo de sustancias.

Por otro lado también encontramos dentro de las calificaciones de las lesiones aquella atinente a la perturbación funcional ${ }^{44}$, entendida como: "alteración aunque sea en mínima parte, como lo afirma el Profesor Uribe Cualla, y el de supresión de una función orgánica sin que criterio distinto, como la imperfección estética o la modificación de las formas propias de la euritmia corporal, tenga que ver nada para fijar su alcance, porque no se trata de deformidad física ni de desfiguración facial, en las que se atiende preferentemente a aquel criterio" 45 . Constituye la tercera modalidad de lesión prevista por la Ley 599 de 200 en su artículo 114.

El concepto de perturbación no se agota en los efectos físicos que la agresión puede causar, y el legislador colombiano también anticipó los efectos de una perturbación psíquica $^{46}$ que pudieran derivarse de la agresión propiciada. Este tipo de lesión se define como:

... un daño o desmejoría en la salud mental del ofendido causado sin que medie un daño físico u orgánico. En estos casos, los agentes vulnerantes son actuaciones o mecanismos psicológicos tales como amenazas, chantajes, coacción que obligan a la persona a vivir una experiencia frustrante o lesiva, que desborda su capacidad adaptativa normal frente a un estímulo determinado o estrés, y ocasiona una alteración psíquica que interfiere de manera importante con su adecuado desenvolvimiento personal y social ${ }^{47}$.

Finalmente el Código Penal colombiano contempla una última modalidad de lesión, la pérdida anatómica o funcional de un órgano ${ }^{48}$, la cual "implica la privación de

44 "Artículo 114. Perturbación funcional. Si el daño consistiere en perturbación funcional transitoria de un órgano o miembro, la pena será de prisión de dos (2) a siete (7) años y multa de quince (15) a veinticinco (25) salarios mínimos legales mensuales vigentes.

"Si fuere permanente, la pena será de tres (3) a ocho (8) años de prisión y multa de veintiséis (26) a treinta y seis (36) salarios mínimos legales mensuales vigentes".

45 Corte Suprema de Justicia, Sala de Casación Penal. Sentencia del 18 de julio de 1992, M.P.: ÁnGEL MARTín VÁSQUEZ.

46 “Artículo 115. Perturbación psíquica. Si el daño consistiere en perturbación psíquica transitoria, la pena será de prisión de dos (2) a siete (7) años y multa de veintiséis (26) a cuarenta (40) salarios mínimos legales mensuales vigentes. Si fuere permanente, la pena será de tres (3) a nueve (9) años de prisión y multa de veintisiete (27) a cincuenta (50) salarios mínimos legales mensuales vigentes”.

47 Instituto Nacional de Medicina Legal y Ciencias Forenses. Guía Práctica para el Dictamen de Lesiones Personales. Bogotá, 2001, p. 13.

48 “Artículo 116 [del Código Penal]. Pérdida anatómica o funcional de un órgano o miembro. Si el daño 
un órgano, es decir, la parte del cuerpo que cumple determinada función ${ }^{49}$ o el conjunto de tejidos o de órganos de menor importancia que actúan simultáneamente en el ejercicio de una función determinada" 50.

Corolario de lo anterior, es válido afirmar que cuando se despliega la acción de dañar con ácido a una persona debe llevarse a cabo una imputación jurídica de lesiones personales con consecuencia de deformidad en virtud del tercer inciso, ya que se satisfacen a cabalidad los elementos objetivos y subjetivos del tipo penal. Conforme a lo anterior también es preciso señalar que dicha circunstancia agravada cuenta con la especialidad para subsumir otro tipo de conductas y que siendo ley posterior derogaría cualquier ley anterior que regule la materia.

Se soluciona con ello el problema del animus necandi requerido para la tentativa de homicidio y se plantea una mejor posición con respecto al bien jurídico tutelado, puesto que se encuentra dentro de los delitos contra la integridad personal cuya definición no hace referencia únicamente a la integridad e integralidad del cuerpo en su componente físico (que se ve afectado con el contacto existente entre el ácido y la piel), sino a las partes estética y funcional que también se ven lesionadas, y a lo atinente a los elementos mentales y psíquicos, que se quebrantan de igual manera con un ataque de la naturaleza señalada. La integridad personal lleva inmersa también la parte de dignidad humana que sucumbe ante un ataque con sustancia corrosiva, por lo cual engloba en mejor forma la lesión causada.

Bajo este concepto de integridad personal, la doctrina ha señalado que constituye "la integridad física y psíquica de la persona, aquella tanto en su contenido anatómico como fisiológico, y esta -la psíquica-, en su funcionalidad que está ligada indisolublemente a una base somática" 51 .

Desde el punto de vista punitivo también se hace un reproche justo, proporcional y necesario. La pena resultante de un ataque de este tipo es equivalente a las señaladas en los delitos de tortura y de tentativa de homicidio. Cabe indicar que si concurren varios agravantes específicos de las lesiones (que se cometan en el rostro) o de aquellas que remite el Código en virtud del artículo 119 (que remite a los agravantes del

consistiere en la pérdida de la función de un órgano o miembro, la pena será de seis (6) a diez (10) años de prisión y multa de veinticinco (25) a cien (100) salarios mínimos legales mensuales vigentes. "La pena anterior se aumentará hasta en una tercera parte en caso de pérdida anatómica del órgano o miembro".

49 Solórzano Niño, Roberto. Medicina legal, criminalística y toxicología para abogados. Canal Ramírez, 1996, p. 126.

50 Castro Cuenca, Carlos Guillermo. Manual de Derecho Penal.Parte Especial. Colegio Mayor de Nuestra Señora del Rosario, 2010, p. 139.

51 Tocora, Luis Fernando. Derecho Penal Especial. Delitos contra la vida y la integridad personal, el patrimonio económico y delitos sexuales. Librería del Profesional, 2009, p. 6. 
homicidio doloso), tales como que sea con sevicia; por precio, promesa remuneratoria, ánimo de lucro o por otro motivo abyecto o fútil; cuando sea sobre cónyuge o compañero permanente; colocando a la víctima en situación de inferioridad o indefensión o aprovechándose de esta situación; en mujer por el hecho de ser mujer, etc., el marco punitivo podría llegar a ser mayor y por ende el castigo sería más ejemplarizante si lo que se persigue es enviar un mensaje de prevención general y especial negativas a la sociedad.

Según lo anterior, el mejor camino para acompasar la imputación jurídica y la imputación fáctica en los ataques con ácidos debe ser endilgar la conducta bajo el delito de lesiones personales.

\section{CONCLUSIONES}

A lo largo del presente documento se han visto las diferentes etapas que ha recorrido la problemática actual frente a los ataques con sustancias químicas corrosivas. Fue posible dilucidar que debido a su bajo costo y fácil acceso, es cada vez más común la utilización de estos elementos químicos como medio para cometer ataques, pero además fue posible enmarcar esta situación dentro de aquellas que logran ser aún más complejas para el derecho penal colombiano.

Es importante resaltar, a manera de conclusión, que habiendo hecho un examen frente a las tres figuras jurídicas bajo las cuales se ha pretendido imputar este tipo de conductas, no existe ninguna duda de que aquella que debe ser evaluada por los diferentes agentes judiciales es la de lesiones personales dolosas agravadas, puesto que, tal y como se enunció, las características de estas actuaciones criminales no cumplen con los elementos constitutivos de los delitos de tentativa de homicidio y tortura.

Con respecto a la sanción, tendremos que decir que el castigo -en términos de tiempo transcurrido en prisión- podrá ser mayor si se endilga responsabilidad penal por el delito de lesiones personales y no por las conductas de tentativa de homicidio o tortura. Reconocemos que político-criminalmente puede causar un mayor reproche social denominar un ataque con ácido bajo los dos últimos delitos mencionados, pero al momento de imponer una sanción, si el órgano que investiga imputa y acusa por unas lesiones personales dolosas con varios agravantes (deformidad física, con agravante de ser en el rostro, agravante de ser desplegado el daño con una sustancia corrosiva, agravante de ser cometido con motivo fútil o contra mujer por el hecho de ser mujer), el marco punitivo será mayor y la pena a imponer también.

Con respecto a la parte probatoria, será mucho más fácil probar el dolo de la lesión que el ánimo de matar de la tentativa de homicidio. Tampoco será fácil determinar la finalidad de la tortura, por lo cual, a partir de las pruebas, será más sencilla una investigación encaminada a demostrar las lesiones personales que las demás tipologías criminales. 
Vale la pena acotar además el fenómeno legislativo por el cual atraviesa el país. Actualmente, cada una de las situaciones de mayor envergadura mediática logra hacer eco en el Congreso de la República, lo cual a su vez produce un efecto de paño de agua tibia en los grandes incendios provocados por los medios de comunicación. Hoy en día, las propuestas que pretenden ser una solución para este tipo de problemáticas no se destacan por ser evaluadas en cuanto a su prosperidad social, viabilidad jurídica y reparación integral, sino que se presentan como cortinas de humo que finalmente no producen nada concreto.

Es de saber que el país no carece de una reglamentación adecuada para tan dramática situación, por el contrario, desde hace años el derecho penal ha previsto las sanciones a imponer cuando de ataques contra la integridad humana se trata, y las eventualidades criminales no pueden instituirse como figuras independientes y autónomas cada vez que lleguen a los titulares de la prensa; los jueces en Colombia deben ser diáfanos y estrictos en el uso de las figuras ya existentes, realizar el correcto recorrido dogmático frente a cada caso y no titubear ante la presión social; solo así existirá una debida utilización de los medios otorgados por el derecho penal y una correcta aplicación de la ciencia jurídica.

Por último, la problemática de los ataques con ácido debe analizarse no solo jurídicopenalmente sino sociológica, victimológica y criminológicamente. Es preciso llevar a cabo un estudio generalizado que nos indique por qué la sociedad está cometiendo este delito.

\section{BIBLIOGRAFÍA}

\section{Doctrina}

Arboleda Vallejo, Mario y Ruiz Salazar, José Armando. Manual de Derecho Penal. Parte General y Parte Especial. Editorial Leyer, 2007.

Barrera Domínguez, Humberto. Delitos contra la vida y la integridad personal. Ediciones Librería del Profesional, 1995.

Barrientos Restrepo, Samuel. Delitos contra la vida y la integridad personal. Editorial Bedout, 1965.

Bustos Ramírez, Juan. Derecho Penal Especial. Editorial Leyer, 2008.

Castro Cuenca, Carlos Guillermo. Manual de Derecho Penal - Parte Especial. Colegio Mayor Nuestra Señora del Rosario, 2010.

Córdoba Angulo, Miguel. Lecciones de Derecho Penal. Parte General. Universidad Externado de Colombia, 2011. 
Gómez Méndez, Alfonso. Delitos contra la vida y la integridad personal, 3. a ed. Universidad Externado de Colombia, 1998.

Instituto Nacional de Medicina Legal y Ciencias Forenses. Guía Práctica para el Dictamen de Lesiones Personales, 2001.

Instituto Nacional de Medicina Legal y Ciencias Forenses. Requerimiento No. $560-G C R N V-2014$. Respuesta dada el día 8 de septiembre de 2014 a derecho de petición elevado por Ricardo Medina el día 3 de septiembre de 2014.

Luzón Peña, Diego-Manuel. Lecciones de Derecho Penal. Parte General. Tirant lo Blanch, 2012.

MÁRQUez PiÑERo, RAFAEL. El tipo penal. Algunas consideraciones en torno al mismo. Universidad Nacional Autónoma de México, 1992.

Mesa Velásquez, Luis EduARdo. Delitos contra la vida y la integridad personal y delitos contra la propiedad. Universidad de Antioquia, 1968.

Molina Arrubla, Carlos Mario. Delitos contra la vida y la integridad personal. Diké, 1995.

Muñoz Conde, Francisco. Derecho Penal. Parte Especial. Tirant lo Blanch, 2001.

Pérez, Luis Carlos. Derecho Penal. Partes General y Especial. Temis, 1981.

Reyes Echandía, Alfonso. Tipicidad. Temis, 1989.

Ruiz, Carmen Eloísa. Lecciones de Derecho Penal. Parte General. Universidad Externado de Colombia, 2011.

Ruiz, Urbano. Diccionario Índice de Jurisprudencia Penal, t. III. Ministerio de Justicia y de Interior, España, 1989-1992.

SOlÓRZANO NiÑo, RoBERTO. Medicina legal, criminalística y toxicología para abogados. Canal Ramírez, 1996.

Terradillos Basoco, JuAn María. Lecciones y materiales para el estudio del Derecho Penal, t. III, Derecho Penal. Parte Especial, vol. I. Iustel, 2011.

Tocora, Luis Fernando. Derecho Penal Especial. Delitos contra la vida y la integridad personal, el patrimonio económico y delitos sexuales. Ediciones Librería del Profesional, 2009. 
Uribe Cualla, Guillermo. Medicina legal, toxicología y siquiatría forense. Temis, 1977

Valldecabres Ortiz, María Isabel. Imparcialidad del juez y medios de comunicación. Tirant lo Blanch, 2004.

Velásquez, Fernando. Delitos contra la vida y la integridad personal. Jurídicas Andrés Morales, 2013.

Velásquez, Fernando. Manual de Derecho Penal. Parte General. Editorial Librería Jurídica Comlibros, 2007.

Zaffaroni, Eugenio Raúl. Tratado de Derecho Penal. Parte General. Ediar, 1980.

\section{Jurisprudencia}

Corte Constitucional. Sentencia C-587 de 1992, M.P.: Ciro Angarita Barón.

Corte Interamericana de Derechos Humanos, caso Bámaca Velásquez.

Corte Interamericana de Derechos Humanos, caso Bueno Alves vs Argentina.

Corte Interamericana de Derechos Humanos, caso Cantoral Benavides vs. Perú.

Corte Suprema de Justicia, Sala de Casación Penal. Sentencia del 18 de julio de 1992, M.P.: Ángel MaRTín VÁsQueZ.

International Criminal Tribunal for Rwanda. The Prosecutor vs. Jean-Paul Akayesu, case n. ${ }^{\circ}$ ICTR-96-4-T.

JuZgado de Violencia sobre la Mujer n. ${ }^{\circ} 3$ de Madrid. Sentencia 252/2014, Sección n. ${ }^{\circ} 26$ de la Audiencia Provincial de Madrid, Procedimiento sumario ordinario 14/2013, Magistradas D. Teresa Arconada Viguera, D. Pilar Alhambra Pérez y D. Leopoldo Puente Segura.

Juzgado Quinto Penal del Circuito de Santa Marta. Sentencia del 17 de julio de 2000 , causa . $^{\circ} 2000-0057$.

Sentencia T.S. 1070/2011 (Sala 2) del 13 de octubre de 2011, Villa de Madrid, España.

\section{Noticias}

“Ataques con ácido no son castigados en Pakistán”, El Tiempo, 5 de mayo de 2014. 
"Desde 2004 en Colombia se denunciaron 926 ataques con ácido", Caracol Radio, 29 de marzo de 2014.

"Publican audios de falsa denuncia de ataque con ácido", El Tiempo, 30 de abril de 2014.

"Van 15 mujeres atacadas con ácido este año en Bogotá", El Tiempo, 5 de septiembre de 2014 .

\section{Normativa}

Constitución Política de Colombia de 1991.

Código Penal colombiano de 1936.

Código Penal colombiano de 2000.

Ley 1639 de 2013. 